Journal Of Al Azhar University Engineering Sector

Vol. 12, No. 42, January, 2017, 223-232

\title{
EFFECT OF CA/P AND PH IN THE WET-SYNTHESIS REACTION ON THE FORMATION OF DIFFERENT CALCIUM PHOSPHATE PHASES
}

\author{
M. Habib, K. Hussein and N. Fatahalla \\ Mechanical Engineering Department, Al-Azhar University, Cairo, Egypt.
}

\begin{abstract}
Recently, there has been a growing new paradigm to use synthetic calcium phosphate biomaterials as bone substitutes in orthopedics applications. Their structure and composition are close to the human bone, and thus conferring them a good biocompatibility and osteoconductivity. Wet process is normally used for the synthesis of Hydroxyapatite (HA) and beta-tricalcium phosphate $(\beta-\mathrm{TCP})$. However, the wet process was reported to be less reproducible for fabrication of pure apatitic phases in comparison to other synthesis processes. In this study, it is hypothesized that a specific apatitic phase that is normally obtained from stoichiometric reaction can be synthesized by using non-stoichiometric based reactants in a reproducible way by controlling the $\mathrm{pH}$ value during the synthesis process. A factorial design with two factors and three repeats was implemented to examine the hypothesis $[\mathrm{A}: \mathrm{Ca} / \mathrm{P}(1.5$, $1.55,1.667)$ and $\mathrm{B}: \mathrm{pH}(7.5,9.5)]$. All precipitated powders were dried and aged overnight and then sintered for 2 hours at $800{ }^{\circ} \mathrm{C}$. The powders were analyzed for phase, group and morphological analysis by X-Ray Diffraction (XRD), FTIR, and ESM/TEM, respectively. The results have revealed a better understanding of how to synthesize pure calcium phosphates phases for the repair of bone defects using the cost-effective wet chemical process. Small variation in the reactant molar ratio can significantly change the precipitated phases. Controlling the reaction $\mathrm{pH}$ can governor effectively the precipitation of a specific phase despite of the small variation in the molar ratio.
\end{abstract}

\section{KEYWORDS : Biomaterials, Calcium Phosphate Phases, Hydroxyapatite, Beta-Tricalcium Phosphate, Wet Process}

\section{INTRODUCTION}

Bone repair remains an important challenge in the field of dental maxillofacial and orthopedics when there is an urgent need for bone reconstruction. Bone defectcan be treated with orthopedic surgery by replacing the defected bones with bone substitutes. There are two types of bone substitutes, biological and synthetic ones [1]. Biological bone substitutes include autograft, allograft, and demineralized bone matrix. In autograft, bone substitute is harvested from the patient himself usually from iliac bone. Whereas the source of bone substitute in allograft is a person other than the patient such as donor or cadaver. The demineralized bone matrix is allograft bone in which inorganic minerals are removed leaving behind the organic (collagen) matrix. The other types of bone substitutes are synthetic bone substitute materials. They have artificial 
mineral structures similar to the mineral content of human bone such as calcium phosphate ceramics, calcium sulfate, and bioactive glasses [2].

Synthetic bone substitute comes to be an optimum alternative for bone allograft. This is due to the excellent biocompatibility nature, no risk of disease/virus transfer, unlimited supply, long shelf life, and availability in every shape, porosity, and composition [3].

Calcium phosphate bioceramics have different phases that can be used as a synthetic bone substitutes. The most commonly used phases are Hydroxyapatite (HA) $\left[\mathrm{Ca}_{10}\left(\mathrm{PO}_{4}\right)_{6}(\mathrm{OH})_{2}\right]$, betatricalcium phosphate $\left(\beta\right.$-TCP), alpha-tricalcium phosphate $(\alpha-\mathrm{TCP})\left[\mathrm{Ca}_{3}\left(\mathrm{PO}_{4}\right)_{2}\right]$ and biphasic calcium phosphate $(\mathrm{BCP})$ which is a combination of both in various ratios.

Fabrication of calcium phosphate ceramics can be made by several techniques such as wet chemical process, hydrothermal processing, sol gel technique, solid state technique, and selfpropagating combustion synthesis. Wet chemical process is considered as the most widely researched technique because it produces large amount of powders with reasonable cost [4]. However, the effect of some process parameters is still misunderstood and consequently reproducible data are needed.

This investigation is focused on stabilizing the synthesis process parameters. Namely, Calcium to Phosphate Ratio $(\mathrm{Ca} / \mathrm{P})$ and $\mathrm{pH}$ value are controlled for a reproducible synthesis of hydroxyapatite (HA) and Beta-Tri-calcium Phosphate ( $\beta$-TCP) that meet the international norms of orthophosphates used in orthopedic application.

HA and $\beta$-TCP powders can be produced via wet-chemical process as a precipitation by a chemical reaction between the two reactants calcium nitrate tetra-hydrate $\left[\mathrm{Ca}\left(\mathrm{NO}_{3}\right)_{2} \cdot 4 \mathrm{H}_{2} \mathrm{O}\right]$ and di-ammonium hydrogen orthophosphate $\left[\left(\mathrm{NH}_{4}\right)_{2} \mathrm{HPO}_{4}\right]$.

In order to produce a specific phase of calcium phosphates, a $\mathrm{Ca} / \mathrm{P}$ ratio of the reactants must be taken into consideration according to the following chemical reactions:

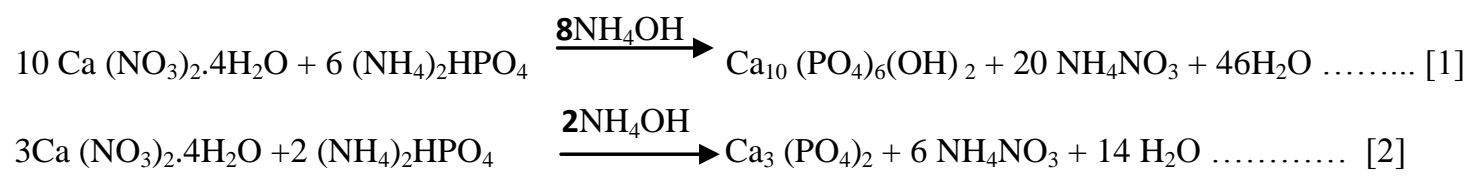

According to equation [1], HA can be synthesized when the reactants molar ratio of $\mathrm{Ca} / \mathrm{P}$ equals to $10 / 6=1.667$ [5-7]. On the other hand, $\beta$-TCP can be synthesized according to equation [2] when the reactants molar ratio of $\mathrm{Ca} / \mathrm{P}$ equals to $3 / 2=1.5$ [8-11]. However, pure $\beta$-TCP is reported to be precipitated at $\mathrm{Ca} / \mathrm{P}=1.41[7]$. Whereas, in other research work [12], pure $\beta$-TCP was easily precipitated at different $\mathrm{Ca} / \mathrm{P}$ ranging from 0.67 to 1.55 .

The reaction $\mathrm{pH}$ value controls the $\mathrm{Ca} / \mathrm{P}$ ratio of the precipitated powders [12]. For example, at $\mathrm{pH}$ equals 6 , the precipitated powder will have a $\mathrm{Ca} / \mathrm{P}$ lower than 1.5 . When the $\mathrm{pH}$ of the reaction increases to 7.4 , the $\mathrm{Ca} / \mathrm{P}$ of the precipitated powders will be approximately equal to 1.5 [12]. If the $\mathrm{pH}$ is maintained at 8.5 , the $\mathrm{Ca} / \mathrm{P}$ ratio of the precipitated powders will increase with nonlinear behavior till it reaches 1.66 [12].

The $\mathrm{pH}$ of the reaction can be controlled by adding ammonium hydroxide $\left[\mathrm{NH}_{4} \mathrm{OH}\right]$ solution. If the reaction between two reactants is a precipitation reaction, one of the reactants should be in a limiting weight that is calculated from the coefficient of the balanced equation and the other reactant should be in excess weight to attain maximum yield of the product. This indicates that the product of precipitation reactions will not change even if one the reactant is in rich weight.

In the present work, it is hypothesized that product of stoichiometric precipitation reaction will not change with different reactants molar ratio as long as one of the reactants is in a limiting weight and $\mathrm{pH}$ of the reaction is constant. An experimental work is designed to examine the null hypothesis.

\section{Materials and Method}

The following chemicals were used to synthesis different calcium phosphate phases in a powder form in order to verify the proposed hypotheses. Calcium nitrate tetra-hydrate $\left[\mathrm{Ca}\left(\mathrm{NO}_{3}\right) \cdot 4 \mathrm{H}_{2} \mathrm{O}\right]$ 
(Sigma Aldrich, Germany) was used as a source of calcium $\mathrm{Ca}^{2+}$ ions. Di-ammonium hydrogen orthophosphate $\left[\left(\mathrm{NH}_{4}\right)_{2} \mathrm{HPO}_{4}\right]$ (Sigma Aldrich, India) was used as a source of phosphate $\left(\mathrm{PO}_{4}\right)^{3-}$ ions. Both salts were dissolved in distilled water. Ammonium hydroxide $\left[\mathrm{NH}_{4} \mathrm{OH}, \leq 33 \% \mathrm{w} / \mathrm{w}\right]$ (EDWIC, Egypt) was used to control pH of the solution.

Wet chemical process was used for the synthesis of all specimens during the course of this study. $\mathrm{Ca}\left(\mathrm{NO}_{3}\right)_{2} \cdot 4 \mathrm{H}_{2} \mathrm{O}$ solution was placed into double wall beaker. Then $\left(\mathrm{NH}_{4}\right)_{2} \mathrm{HPO}_{4}$ solution in separation funnel was added to it. The two solutions were mixed with mechanical stirrer at a speed of $1250 \mathrm{rpm} . \mathrm{pH}$ and temperature of the mixture were monitored by $\mathrm{pH} /$ temperature meter (Genway, UK) via $\mathrm{pH} /$ temperature probe. Synthesis temperature and solution $\mathrm{pH}$ was controlled by constant temperature water circulator and adding $\mathrm{NH}_{4} \mathrm{OH}$ solution.

\section{Factorial Design}

A factorial design with two factors and three repeats was implemented $[\mathrm{A}: \mathrm{Ca} / \mathrm{P}(1.5,1.55,1.667$, 1.72) and $\mathrm{B}: \mathrm{pH}(7.5,9.5)]$. Calcium phosphate $\left[\mathrm{Ca}\left(\mathrm{NO}_{3}\right)_{2} .4 \mathrm{H}_{2} \mathrm{O}\right]$ and di-ammonium hydrogen orthophosphate $\left[\left(\mathrm{NH}_{4}\right)_{2} \mathrm{HPO}_{4}\right]$ were dissolved in distilled water separately according to initial $\mathrm{Ca} / \mathrm{P}$ molar ratio of $1.5,1.55,1.67$ and 1.72 . Synthesis temperature was set at $50{ }^{\circ} \mathrm{C}$ and $\mathrm{pH}$ of the reaction was maintained at 7.5 and 9.5 by adding ammonium hydroxide $\left[\mathrm{NH}_{4} \mathrm{OH}\right]$. There were three repeats of each $\mathrm{Ca} / \mathrm{P}$ and $\mathrm{pH}$ combination. The experimental work is carried out by making initial $\mathrm{Ca} / \mathrm{P}=1.72$ and 1.55 . The resulting phases were then compared to those obtained from the stoichiometric reaction in which $\mathrm{Ca} / \mathrm{P}=1.67$ and 1.5 . The reaction $\mathrm{pH}$ was maintained at 9.5 and 7.5 for $\mathrm{Ca} / \mathrm{P}=(1.667$ and 1.72$)$ and (1.5 and 1.55) respectively. Precipitated powder was aged for 24 hours at room temperature $\left(28{ }^{\circ} \mathrm{C}\right)$. Aged powder was then filtrated in Buchner funnel and washed three times with distilled water. Filtrated powder was dried at $80{ }^{\circ} \mathrm{C}$, for 20 hours. Finally, dried powders were sintered at $800{ }^{\circ} \mathrm{C}$ for 2 hours.

\section{Characterization}

All precipitated powders were analyzed for phase identification and crystal size by X-ray diffraction (XRD) (using Axs-D8 Advance, Bruker). The measurements were done by using metal ceramic tube copper (with $\mathrm{Cu} \mathrm{K}$-alpha wave length=1.5405981 $\mathrm{A}^{\mathrm{o}}$ ) at the following conditions: $1600 \mathrm{~W}, 40 \mathrm{kV}, 40 \mathrm{~mA}$ and scanned the diffraction angles $(2 \theta)$ between $20^{\circ}$ and $60^{\circ}$ with a step size of $0.02^{\circ} 2 \theta$ per second. Functional groups of as precipitated and sintered powders were identified by Fourier transform infrared (FTIR) spectroscopy (FT-IR spectrometer 6100 , JASCO, Japan, using $\mathrm{KBr}$ pellet technique in the range $4000-400 \mathrm{~cm}^{-1}$, with a resolution of $8 \mathrm{~cm}^{-1}$ ). KBr salt was mixed with the powder sample, the concentration of the sample in $\mathrm{KBr}$ should be in the range of $0.2 \%$ to $1 \%$. The mixture was ground and then pressed in mini-press to form a small transparent pellet (a disc of 1-2 $\mathrm{mm}$ thick and $1 \mathrm{~cm}$ in diameter). The resulting pellet is an IR sample. After that the transparent pellet is held by a sample holder and the IR beam of the spectrometer can pass through it. Morphology of the as precipitated and sintered powders were examined using scanning electron microscope (SEM) (JEOL, JSM- 5500 LV, Japan) after coating with a thin layer of gold using (SPI-module- Jap). Morphology of nano-particles was determined by JEOL 1010 transmission electron microscope; Japan, operated at $80 \mathrm{kV}$ accelerating voltage. Powder samples were suspended in ethanol and ultrasonicated for 30 minutes to yield a very dilute suspension. $2 \mathrm{~mm}$ diameter carbon coated grids (CCG) were dipped in the suspension and were extracted and dried prior to use in a single tilt holder of the TEM.

\section{Results}

HA was synthesized at room temperature, without sintering, from the stoichiometric reaction $(\mathrm{Ca} / \mathrm{P}=1.667)$ at a controlled $\mathrm{pH}=9.5$. XRD patterns of as-precipitated powder synthesized at $\mathrm{pH}=$ 9.5 and $\mathrm{Ca} / \mathrm{P}=1.67$ and 1.72 are shown in Figure (1). It can be seen that, XRD patterns of the as precipitated powders are identical in shape. XRD analysis determined that both patterns corresponded to the standard JCPDS card no: 67-0694 for HA phase.

The corresponding FTIR results of the first group are depicted in Figure (2). FTIR spectrum confirmed the results of XRD that the as precipitated powders are hydroxyapatite. Vibrational 
modes of $\mathrm{PO}_{4}$ group were observed at 473, 574, 607, 960, and 1040-1120 $\mathrm{cm}^{-1}$. The band at 3570 $\mathrm{cm}^{-1}$ was assigned to $\mathrm{OH}$ group. Peaks at 3424 and $1627 \mathrm{~cm}^{-1}$ can be attributed to the adsorbed water $[8,10,12]$.

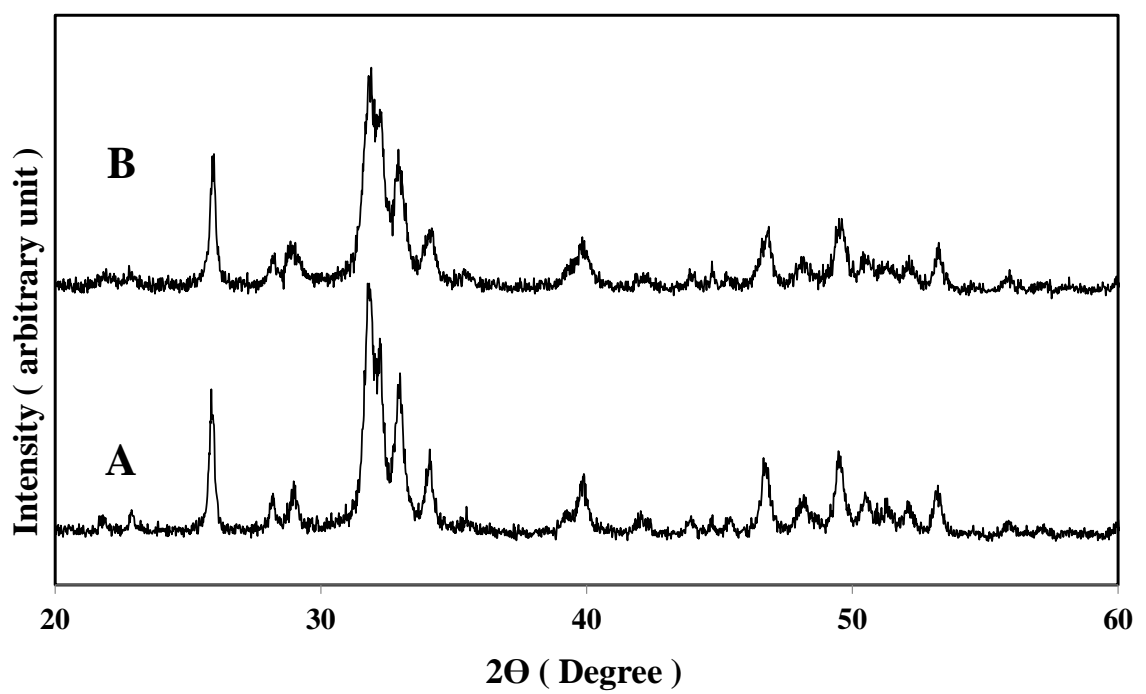

Fig. 1 XRD patterns of as precipitated $\mathrm{HA}$ powders prepared at $\mathrm{pH}=9.5$ and $\mathrm{Ca} / \mathrm{P}=\mathrm{A}) \mathbf{1 . 6 7}$ and $\mathrm{B}) \mathbf{1 . 7 2}$.

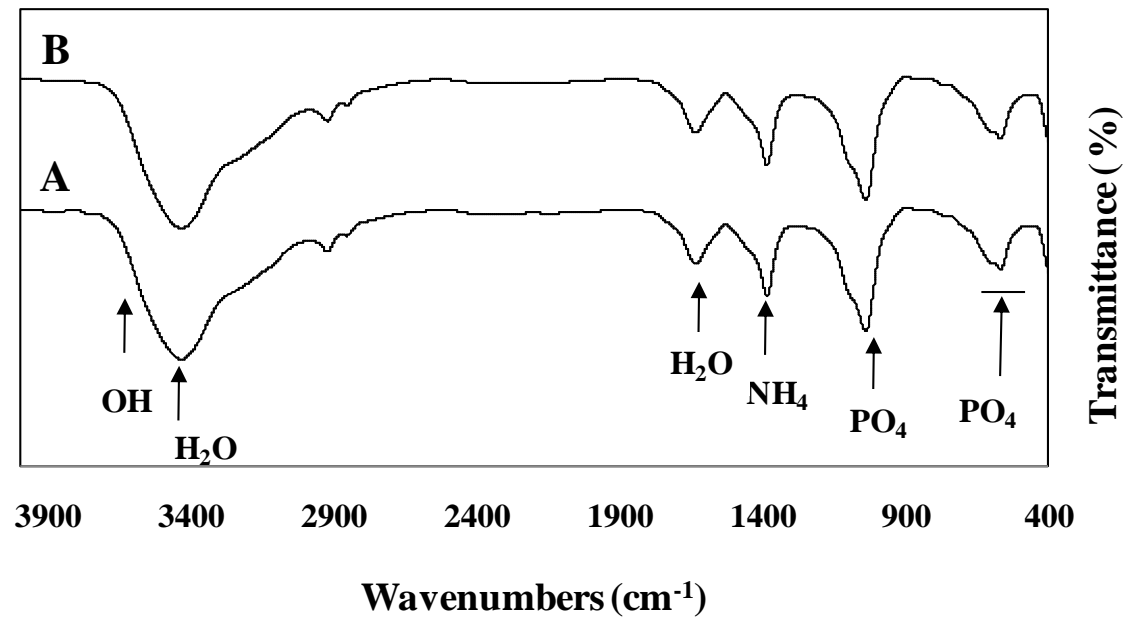

Fig.2 FTIR patterns of as precipitated $\mathrm{HA}$ powders prepared at $\mathrm{pH}=9.5$ and $\mathrm{Ca} / \mathrm{P}=\mathrm{A}) 1.67$ and $\mathrm{B}) 1.72$.

XRD patterns of the as precipitated powders for $\mathrm{Ca} / \mathrm{P}=1.5$ and $\mathrm{Ca} / \mathrm{P}=1.55$ are similar and the revealed that they were poorly crystallized HA. The poorly crystallized HA is believed to be CDHA which is supported by the $\mathrm{Ca} / \mathrm{P}$ ratio of 1.5 and 1.55 (Figure 3 ). Functional groups for asprecipitated powder in the second group are checked by FTIR (Figure 4). FTIR spectrum proved 
that the as precipitated powders are CDHA. Where, Vibrational modes of $\mathrm{PO}_{4}{ }^{-3}$ group were observed at 467, 566, 577, 960 and $1040-1120 \mathrm{~cm}^{-1}$. The band at $3534 \mathrm{~cm}^{-1}$ was assigned to $\mathrm{OH}^{-1}$ group. Peaks at 3418 and $1632 \mathrm{~cm}^{-1}$ can be attributed to the adsorbed water $\left[\mathrm{H}_{2} \mathrm{O}\right]$. The weak peak located at $869 \mathrm{~cm}^{-1}$ may be due to a minute amount of carbonate $\left[\mathrm{CO}_{3}\right]$ or may be for $\mathrm{HPO}_{4}$

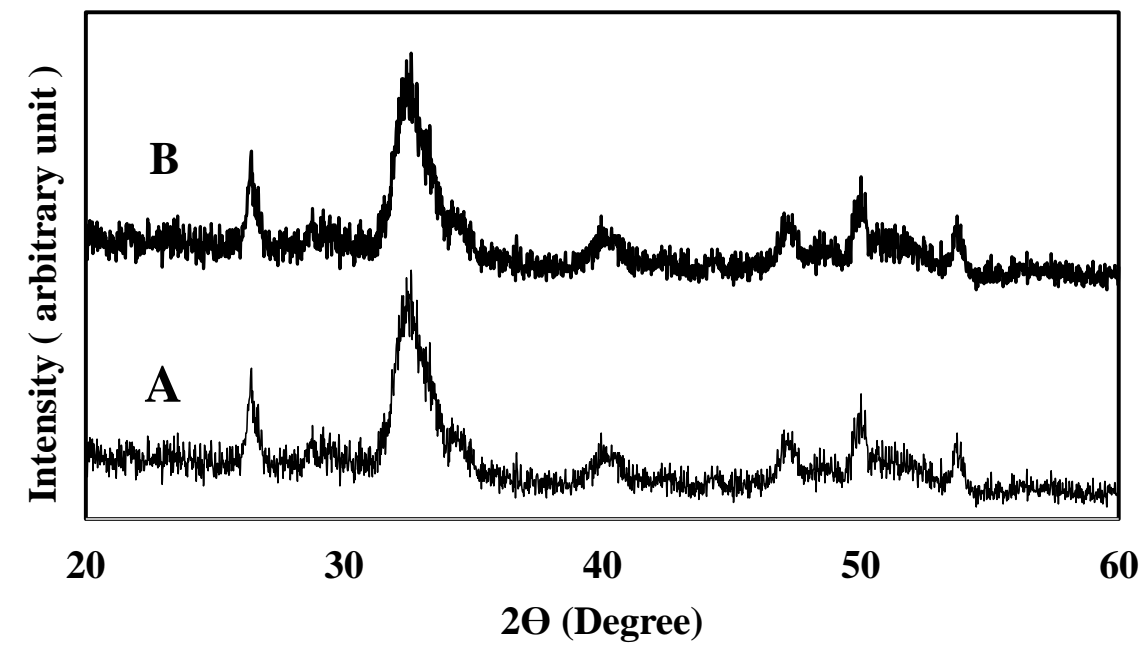

group. However, no vibration modes of $\mathrm{CO}_{3}$ were detected in FTIR spectra near 1490 and 1426 $\mathrm{cm}^{-1}$. Therefore, it is thought that the weak band at $869 \mathrm{~cm}^{-1}$ is a witness characteristic of the $\mathrm{HPO}_{4}$, which is characteristic of CDHA. Additionally, the band at $1380-1403 \mathrm{~cm}^{-1}$ is assigned to residual nitrate group $\left[\mathrm{NH}_{4}\right][10]$.

Fig. 3 XRD patterns of as precipitated powders prepared at $\mathrm{pH}=7.5$ and $\mathrm{Ca} / \mathrm{P}=\mathrm{A}) 1.5$ and $\mathrm{B}) 1.55$.

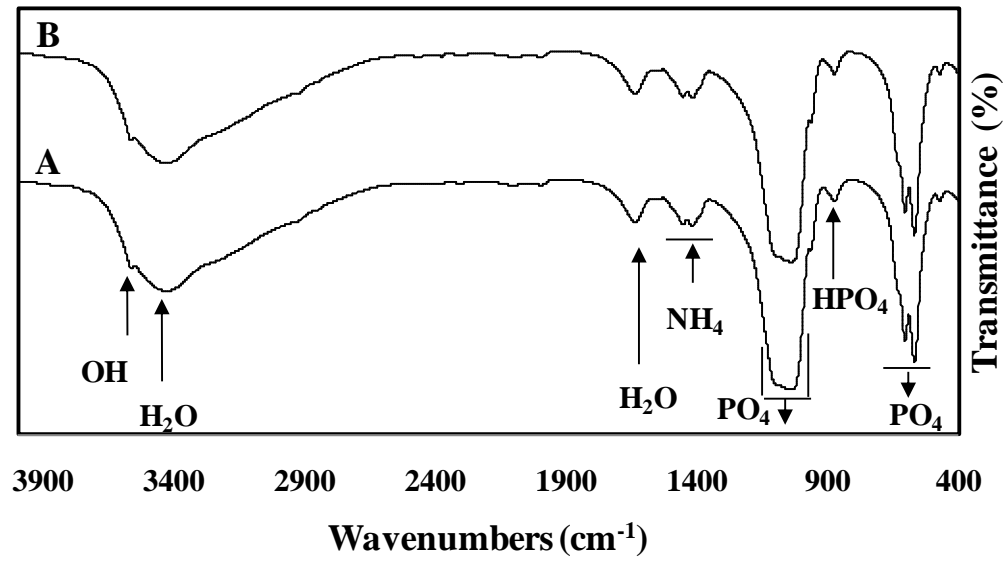

Fig.4 FTIR patterns of as precipitated powders prepared at $A) C a / P=1.5$ and $B$ ) $C a / P=1.55$ and constant

$$
\text { pH=7.5. }
$$

XRD patterns of powders prepared at $\mathrm{Ca} / \mathrm{P}=(1.67$ and 1.72$), \mathrm{pH}=9.5$ and synthesis temperature $=50{ }^{\circ} \mathrm{C}$ and calcined at $800{ }^{\circ} \mathrm{C}$ for 2 hours are shown in Figure (5). XRD patterns for the two sets of $\mathrm{Ca} / \mathrm{P}$ are identical and revealed that the calcinated powder is pure $\mathrm{HA}$ and no other phases were detected. This is confirmed from the agreement of peaks of the patterns with standard 
JCPDS card no: 67-0694 for stoichiometric HA. Crystal size increased from $27.28 \pm 14.54 \mathrm{~nm}$ to $73.35 \pm 10.11 \mathrm{~nm}$ with calcination process.

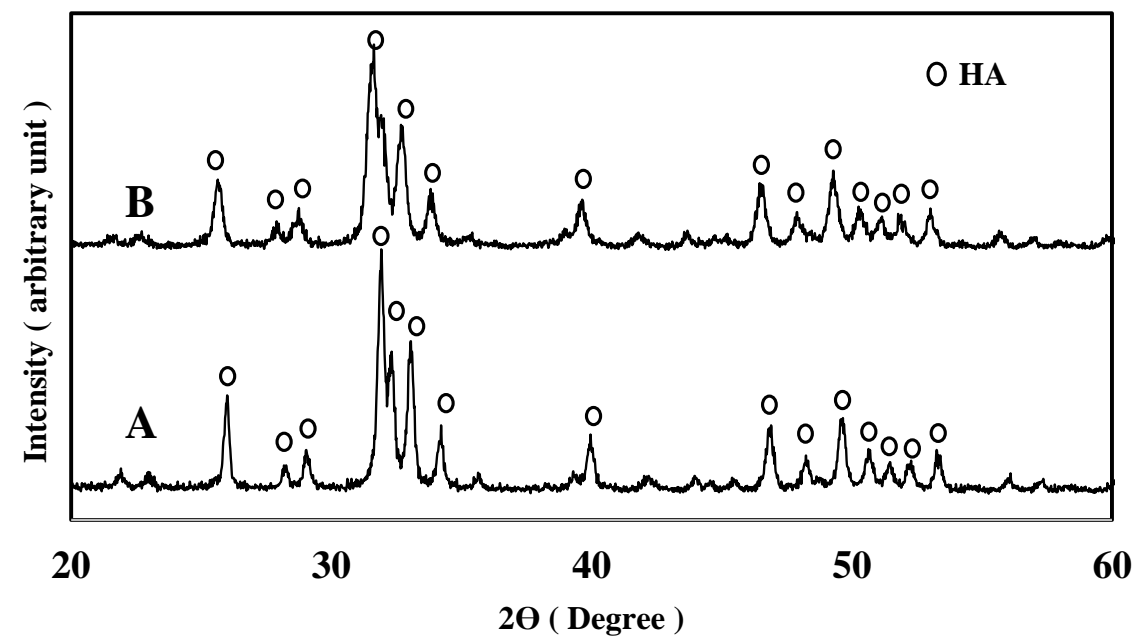

Fig. 5 XRD patterns of powders calcined at $800{ }^{\circ} \mathrm{C}$ for 2 hours and was synthesized at $\mathrm{pH}=9.5$ and $\mathrm{Ca} / \mathrm{P}=\mathrm{A}$ )

\subsection{7 and B) 1.72 .}

XRD patterns of the powder synthesized at $\mathrm{Ca} / \mathrm{P}=(1.5$ and 1.55$), \mathrm{pH}=7.5$, synthesis temperature $=35^{\circ} \mathrm{C}$ and that is calcined at $800^{\circ} \mathrm{C}$ have similar patterns and are presented in Figure (6). The peaks of XRD patterns correspond to standard JCPDS card no: $70-2065$ for pure $\beta$-TCP. These results indicated that $\mathrm{CDHA}$ have been transformed to a single phase of $\beta$-TCP. Crystal size increased from $128.5 \pm 31.5 \mathrm{~nm}$ to $156 \pm 105.44 \mathrm{~nm}$ with calcination process.

TEM and SEM were used to study the morphology and the particle size of the as-precipitated powders. SEM is suitable for studying the micro-scale particle size morphology. On the other hand, TEM is better in evaluating the nano-size particles.

Figure (7) represents TEM images of as-precipitated powder. It demonstrated that the asprecipitated powder is in nano-scale and takes the shape of rod-like particle. Average diameter was $15.46 \pm 4.34 \mathrm{~nm}$ and the average length was $58.54 \pm 16.26 \mathrm{~nm}$. 


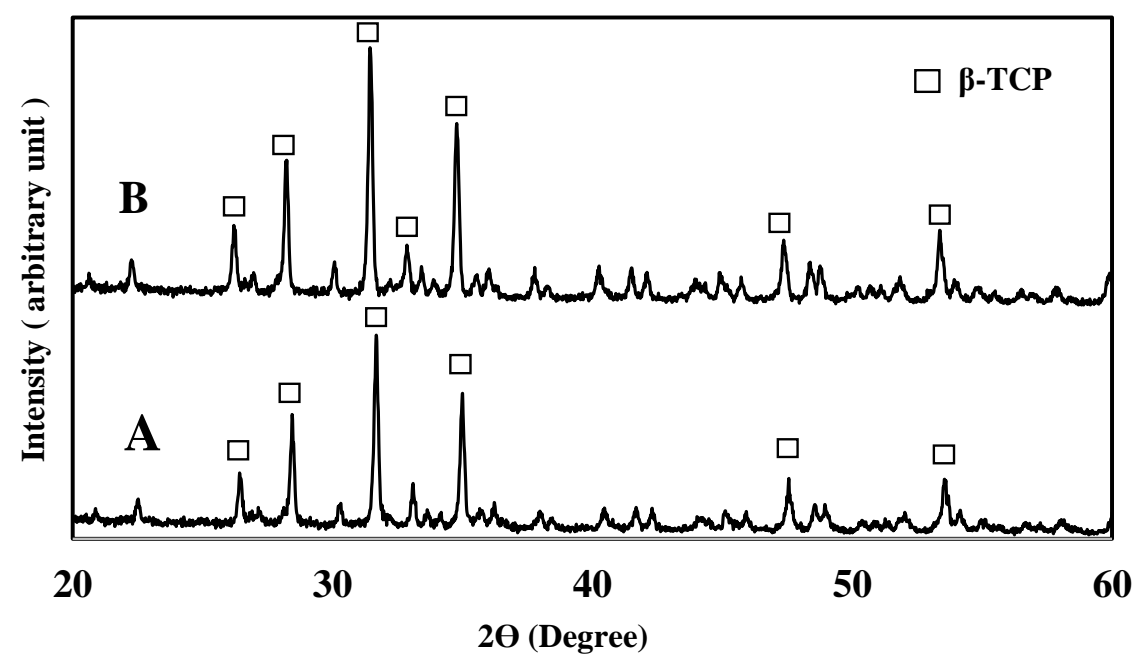

Fig. 6 XRD patterns of powders calcinated at $800{ }^{\circ} \mathrm{C}$ for 2 hours and was prepared at $\mathrm{pH}=7.5$ and $\mathrm{Ca} / \mathrm{P}=\mathrm{A}$ )

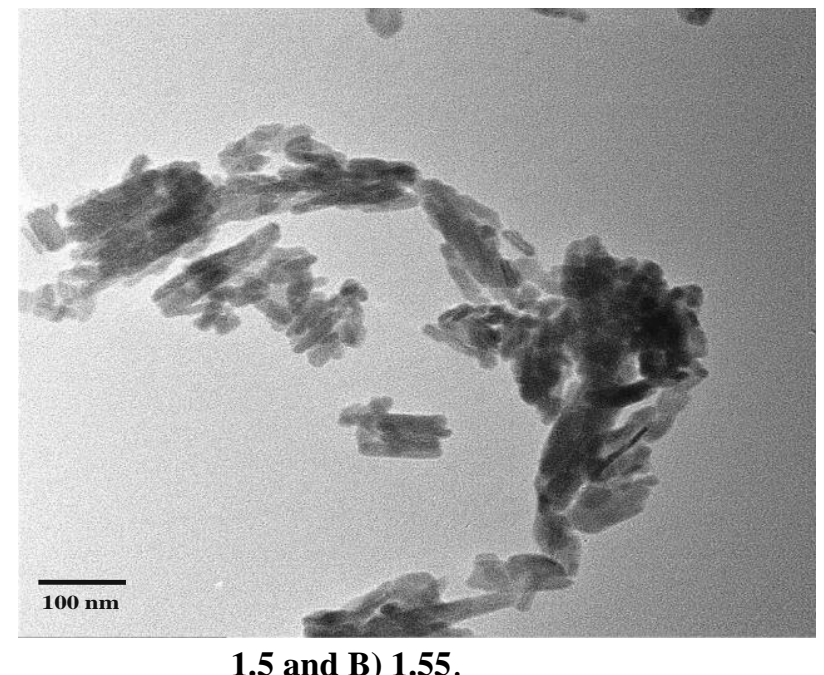

Fig.7 TEM image of as precipitated $\mathrm{HA}$ powders synthesized at $\mathrm{pH}=9.5$ and $\mathrm{Ca} / \mathrm{P}=(1.67$ and 1.72$)$

Figure (8) shows SEM image which determined the effect of sintering process on the morphology of calcined powders. The HA particles have two different morphologies after calcination. Some of HA particles have hexagonal-like shape. Whereas, the other particles are agglomerated and the necking among the particles is apparent. $\beta$-TCP powders' morphology seems to be quite agglomerated with nearly spherical particles (Figure 9). 


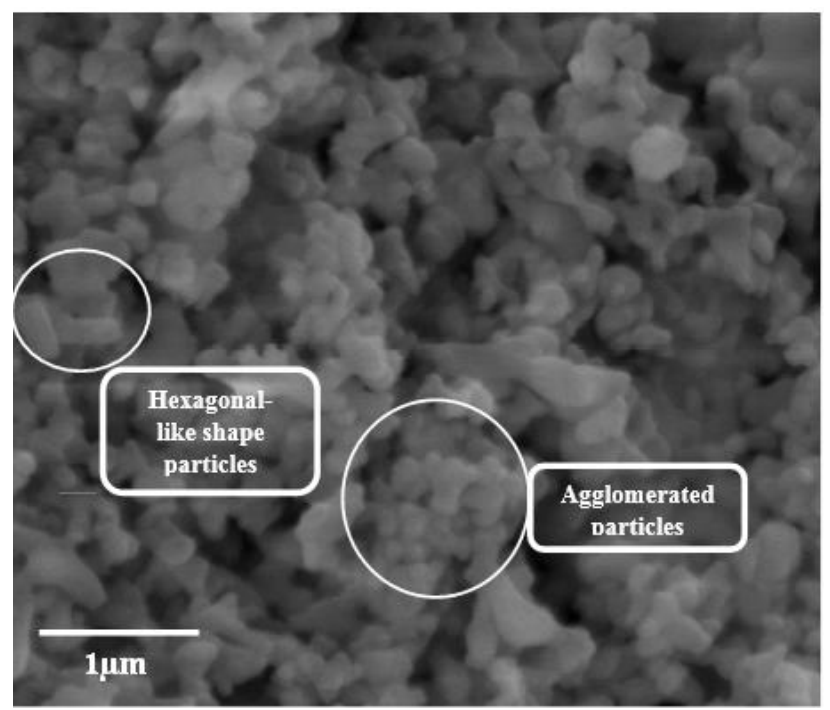

Fig. 8 SEM of HA powders calcined at $800^{\circ} \mathrm{C}$ for 2 hours, prepared at $\mathrm{Ca} / \mathrm{P}=(1.67$ and 1.72$)$ and $\mathrm{pH}=9.5$.

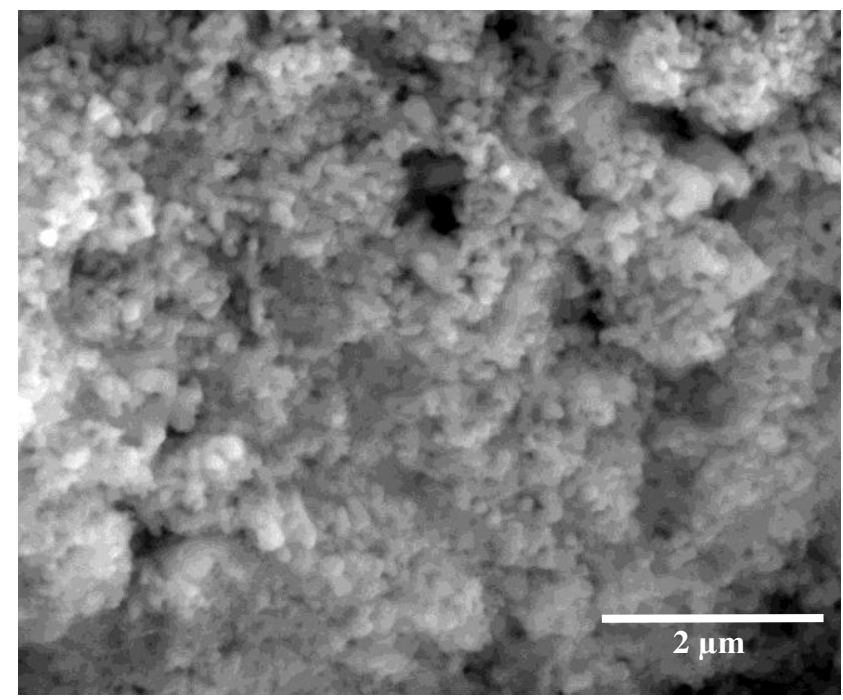

Fig. 9 SEM of $\beta$-TCP powders calcinedat $800{ }^{\circ} \mathrm{C}$ for 2 hours, prepared at $\mathrm{pH}=7.5$ and $\mathrm{Ca} / \mathrm{P}=(1.5,1.55)$

\section{DISCUSSION}

There are different synthesis conditions in wet chemical process that affect the fabrication of HA and $\beta$-TCP phases. The proposed hypothesis in this work presumes that fabrication of HA and $\beta$ TCP phase by wet chemical process can be produced with slight difference in reactants molar ratio $[\mathrm{Ca} / \mathrm{P}$ ratio $]$ as long as $\mathrm{pH}$ of the reaction is maintained at a constant value.

To examine this hypothesis, the reactant $\left[\mathrm{Ca}\left(\mathrm{NO}_{3}\right) \cdot 4 \mathrm{H}_{2} \mathrm{O}\right]$ has been chosen to be the rich reactant and $\left[\left(\mathrm{NH}_{4}\right)_{2} \mathrm{HPO}_{4}\right]$ is a limiting one. The resulting phases obtained from the stoichiometric reaction in which $\mathrm{Ca} / \mathrm{P}=1.67$ and 1.5 were $\mathrm{HA}$ and $\beta$-TCP respectively. The same phases were obtained by non-stoichiometric carried out by making initial $\mathrm{Ca} / \mathrm{P}=1.72$ and 1.55 respectively by controlling the reaction $\mathrm{pH}$. The reaction $\mathrm{pH}$ was maintained at 9.5 and $7.5 \mathrm{for} \mathrm{Ca} / \mathrm{P}=(1.667$ and $1.72)$ and (1.5 and 1.55) respectively. 
XRD and FTIR results of the two reactions have supported the proposed hypothesis. The reactants of precipitation process after dissolved in distilled water became ions. Therefore, during reaction, all ions of the limiting reactant $\left[\left(\mathrm{NH}_{4}\right)_{2} \mathrm{HPO}_{4}\right]$ reacted with the ions of rich reactant $[\mathrm{Ca}$ $\left(\mathrm{NO}_{3}\right) \cdot 4 \mathrm{H}_{2} \mathrm{O}$ ]. In this case, excess ions in rich reactant couldn't find partners to react with. Therefore, the excess amount of rich reactant did not affect the product of precipitation reaction. XRD results of as HA phase that was synthesized at constant $\mathrm{pH}=9.5$ and at different $\mathrm{Ca} / \mathrm{P}(1.667$ and 1.72) molar ratio show no difference in the patterns and therefore, supporting the presumed hypothesis (Figure 1). As-synthesized HA powders remains stable and shows the HA phase after calcination process at $800{ }^{\circ} \mathrm{C}$ (Figure 5). Yet, XRD patterns of the as-synthesized HA powders are poorly crystalline due to their wide and low intensity of peaks (Figure 1). Whereas, crystallinity has been increased by sintering process. Therefore, calcined HA powders have XRD patterns with higher diffraction intensities along with shaper and more narrow peaks (Figure 5).

Similarly, $\beta$-TCP phase that was successfully synthesized at constant $\mathrm{pH}=7.5$ and at two different $\mathrm{Ca} / \mathrm{P}$ molar ratio [1.5 and 1.55] showed no difference in the patterns and therefore, supporting the presumed hypothesis (Figure 6).

XRD results have been supported by FTIR results shown in Figures (2 and 4). Figure (2) represents FTIR response of as-synthesized HA at different $\mathrm{Ca} / \mathrm{P}$ molar ratio (1.667 and 1.72). Whereas, figure (4) shows the FTIR patterns for as-precipitated $\beta$-TCP powders. The bands of vibration modes of $(\mathrm{OH})$ and $\left(\mathrm{PO}_{4}\right)$ groups have been recognized in both as-precipitated HA powders. In addition, water $\left(\mathrm{H}_{2} \mathrm{O}\right)$ and $\mathrm{NH}_{4}$ groups are also identified. $\mathrm{H}_{2} \mathrm{O}$ and $\mathrm{NH}_{4}$ groups are considered as an acceptable contamination because they are already existing in biological bone. Moreover, these groups have no significant effect on XRD results.

The morphology of as-precipitated powders can take different shapes by controlling synthesis conditions. Morphology of as-precipitated powders of HA presented in Figure (7) has a needle like shape. This result is matching with $[5,13]$. Wang et al [14] reported that morphology of asprecipitated HA powders can be changed with the initial $\mathrm{pH}$ values and reaction temperatures [14]. Both $\mathrm{pH}$ and temperature play important roles in the phase formation of HA and its crystal habit, which resulted in various morphologies of HA. The effect of calcination temperature on morphology can be seen in Figure (8). Most of the calcined particles were diffused together and forming a neck-shape due to sintering process (Figure 8).

\section{CONCLUSION}

Wet chemical process has been proved to be an effective technique for producing different phases of calcium phosphate ceramics [HA, and $\beta$-TCP]. It produces homogenous phase as well as large amount of powders with reasonable cost. The combined effect of both the reactants $\mathrm{Ca} / \mathrm{P}$ molar ratio and $\mathrm{pH}$ value was studied. Slight difference in the reactant molar ratio can affect the synthesized phases dramatically. However, this slight difference can be reduced by controlling exactly the $\mathrm{pH}$ value. Sintering temperature is important to control the crystal size and the phase percentage especially when biphasic $\mathrm{Ca} / \mathrm{P}$ is anticipated.

\section{REFERENCES}

1- Mumford J E and Simpson A H R W. Management of Bone Defects: A Review of Available Techniques, Iowa Orthop J.; 12(1992)42-49.

2- Calori G M, Mazza E, Colombo M, Ripamonti C. The use of bone-graft substitutes in large bone defects: Any specific needs?.Injury, Int. J. Care Injured; 42(2011)S56-S63.

3- Zhang M, Wu C, Li H, Yuen J, Chang J, Xiao Y. Preparation, characterization and invitro angiogenic capacity of cobalt substituted $\beta$-tricalcium phosphate ceramics. J. Mater. Chem.; 22(2012)21686-21694.

4- Arends, Christoffersen J, Christoffersen J, Eckert M R, Fowler H, Heughebaert B O, Nancollas J C, Yesinowski G H, Zawacki J P. Calcium hydroxyapatite precipitated from an aqueous solution. An international multimethod analysis. Journal of crystal growth 84(1987) 515-532. 
EFFECT OF CA/P AND PH IN THE WET-SYNTHESIS REACTION ON THE FORMATION OF DIFFERENT CALCIUM PHOSPHATE PHASES

5- Liu X, Zhao M, Lu J, Ma J, Wei J, Wei S. Cell responses to two kinds of nanohydroxyapatite with different sizes and crystallinities. International Journal of Nanomedicine;7(2012) 1239-1250.

6- Ramesh S. Tanb CY, Toloueib R, Amiriyanb M, Purbolaksonoa J, Sopyanc I, Teng W D. Sintering behavior of hydroxyapatite prepared from different routes. Materials and Design 34(2012) 148-154.

7- Kannan S, Rocha J H G, Ventura J M G, Lemos A F, Ferreira J M F. Effect of Ca/P ratio of precursors on the formation of different calcium apatitic ceramics-An X-ray diffraction study. ScriptaMaterialia; 53(2005) 1259-1262.

8- Mirhadi B, Mehdikhani B, Askari N Synthesis of nano-sized B-tricalciumphosphate via wet precipitation. Processing and Application of Ceramics 5 [4] (2011) 193-198.

9- Zhang X,Jiang F, Groth T, Vecchio K S. Preparation, characterization and mechanical performance of dense $\beta$-TCP ceramics with/ without magnesium substitution. $\mathbf{J}$ master sci: mater med;19(2008)3063-3070.

10- Liou S C, Chen S Y. Transformation mechanism of different chemically precipitated apatitic precursors into $\beta$ - tricalcium phosphate upon calcination. Biomaterials; 23(2002)4541-4547.

11-Salahi E, Heinrich J G. Synthesis and thermal behaviour of $\beta$ tricalcium phosphate precipitated from aqueous solutions. British ceramic transactions; 102 [2] (2003) 79-82.

12- Kwon S H,Jun Y K, Hong S H, Kim H E. Synthesis and dissolution behavior of $\beta$-TCP and HA/ $\beta$-TCP composite powders, Journal of the European Ceramic Society; 23(2003) 1039-1045.

13- Zanotto A, Saladino M L, Martino D C, Caponetti E. Influence of temperature on calcium hydrox yapatite nanopowders. Advanced in nanoparticles; 1(2012) 21-28.

14- Wang P, Li C, Gong H, Jiang X, Wang H, Li K. Effects of synthesis conditions on the morphology of hydroxyapatite nanoparticles produced by wet chemical process. Powder Technology; 203(2010) 315-321. 